\title{
Impact of early intravenous amiodarone administration on neurological outcome in refractory ventricular fibrillation: retrospective analysis of prospectively collected prehospital data
}

Dong Keon Lee ${ }^{1}$, Yu Jin Kim¹, Giwoon Kim², Choung Ah. Lee ${ }^{3}$, Hyung Jun Moon ${ }^{4}$, Jaehoon Oh', Hae Chul Yang ${ }^{6}$, Han Joo Choi ${ }^{7}$, Young Taeck Oh ${ }^{1 *+} \mathbb{D}$ and Seung Min Park ${ }^{1 *+}$

\begin{abstract}
Background: The 2015 AHA guidelines recommend that amiodarone should be used for patients with refractory ventricular fibrillation (RVF). However, the optimal time interval between the incoming call and amiodarone administration (call-to-amiodarone administration interval) in RVF patients has not been investigated. We hypothesized that the time elapsed until amiodarone administration could affect the neurological outcome at hospital discharge in patients with RVF.
\end{abstract}

Methods and results: This study is a retrospective analysis of prospectively collected data. One hundred thirty-four patients were enrolled. In univariate logistic regression, the probability of a good neurological outcome at hospital discharge decreased as the time elapsed until amiodarone administration increased (OR 0.89 [95\% Cl=0.80-0.99]). In multivariate logistic regression, the patients who were administered amiodarone in less than 20 min showed higher rates of prehospital ROSC, survival at hospital arrival, any ROSC, survival at admission, survival to discharge, and good CPC at hospital discharge. The call-to-amiodarone administration interval of $\leq 20$ min (OR 6.92, 95\% Cl 1.72-27.80) was the independent factor affecting the neurological outcome at hospital discharge.

Conclusion: Early amiodarone administration ( $\leq 20 \mathrm{~min}$ ) showed better neurological outcome at hospital discharge for OHCA patients who showed initial ventricular fibrillation and subsequent RVF.

Keywords: Cardiopulmonary resuscitation, Emergency medical services, Ventricular fibrillation, Amiodarone, Prognosis

\section{Introduction}

The out-of-hospital cardiac arrest (OHCA) patients who present with initial shockable rhythm (ventricular fibrillation [VF], pulseless ventricular tachycardia) have a good prognosis $[1,2]$, but early defibrillation is crucial for these patients [3]. However, there are patients who do not respond to electrical defibrillation and present

\footnotetext{
* Correspondence: bluethin8505@gmail.com; aukawa1227@gmail.com ${ }^{\dagger}$ Young Taeck Oh and Seung Min Park contributed equally to this work. ${ }^{1}$ Department of Emergency Medicine, Seoul National University Bundang Hospital, 1362082, Gumi-ro 173 Beon-gil, Bundang-gu, Seongnam-si, Gyeonggi-do, Republic of Korea

Full list of author information is available at the end of the article
}

'refractoriness' (persistent VF after more than three defibrillation attempts) $[4,5]$. Sakai et al. reported that the age-adjusted incidence rate of shock-resistant VF was 0.4-0.6 per 100,000 people per year [6].

The 2015 American Heart Association guidelines recommend amiodarone to be used on patients with refractory VF (RVF) [7]. Amiodarone is a class III antiarrhythmic agent (potassium channel blocker) in the Vaughan-Williams classification. It affects ion channels, receptors, and sympathetic activity. It terminates VF by blocking the potassium currents, sodium and calcium channels, and $\alpha$ - and $\beta$-receptor actions [8]. However,

(C) The Author(s). 2019 Open Access This article is distributed under the terms of the Creative Commons Attribution 4.0 International License (http://creativecommons.org/licenses/by/4.0/), which permits unrestricted use, distribution, and 
Kudenchuk reported that amiodarone administration resulted in a higher survival to admission rate without the improvement of survival at discharge or neurologically intact survival in RVF patients [9].

Regarding epinephrine, a correlation between the time of epinephrine administration and the neurological outcome was observed, with early intravenous (IV) epinephrine administration resulting in a better neurological outcome in OHCA with VF [10]. However, there has been no study on the time of amiodarone administration and its association with neurological prognosis.

Therefore, we hypothesized that the time elapsed until amiodarone administration could affect the neurological outcome at hospital discharge in patients with RVF.

\section{Method}

\section{Study protocol}

We performed a retrospective analysis of prospectively collected OHCA data. In South Korea, when a suspected cardiac arrest victim was reported to emergency medical services (EMS), at least two emergency medical technician (EMT) teams are dispatched to perform ALS under the emergency physician's medical control with a video call. The two CPR teams are consistent with a total of 4 to 6 persons, including at least two level-1 EMT and the others were Level-2 EMT or nurses. The level-1 EMTs correspond to EMT paramedics in the United States of America; they are allowed to insert an IV catheter and an advanced airway tube but only under an emergency physician's medical control. Level-2 EMTs correspond to EMT basic [11]. ALS was performed according to the 2015 guidelines of the American heart association (AHA). When VF was seen, rapid defibrillation was performed, and if VF persisted despite three attempts of defibrillation, $300 \mathrm{mg}$ of amiodarone mixed with $5 \%$ dextrose $30 \mathrm{cc}$ were administered to the patient under the emergency physician's medical direction. If VF persisted after $300 \mathrm{mg}$ of amiodarone was injected, an additional $150 \mathrm{mg}$ of amiodarone was administered.

This study was approved by the Institutional Review Board (IRB) of Seoul National University Bundang Hospital (IRB approval number: B-1904537-103) and reported according to the STROBE (Strengthening the Reporting of Observational Studies in Epidemiology) guidelines for reporting observational trials [12].

\section{Patients enrollment and outcomes}

Patients who presented with initial ventricular fibrillation and subsequent RVF were included. RVF was defined as VF that was not terminated after three defibrillation attempts. Patients younger than 18 years and those whose cardiac arrest was caused by nonmedical reasons were excluded.

The primary outcome was the neurological outcome at hospital discharge according to the time elapsed until amiodarone administration, and the secondary outcomes were the prehospital return of spontaneous circulation (ROSC), total ROSC, survival at admission, and survival to discharge according to the time elapsed until amiodarone administration.

The Good-CPC group was defined as those patients whose cerebral performance category (CPC) score was 1 or 2 at hospital discharge, and the Poor-CPC group included those patients who had a CPC of 3-5 at hospital discharge. The CPC score was assessed by emergency physicians at hospital discharge.

\section{Data collection}

We collected Utstein variables, including age, gender, pathogenesis, arrest location, witnessed arrest, first monitored rhythm, bystander cardiopulmonary resuscitation (CPR), response time, defibrillation time, number of shocks, call-to-amiodarone administration interval, callto-epinephrine administration interval, prehospital ROSC, survival at hospital arrival, any ROSC, survival at admission, and survival to discharge.

Pathogenesis was defined as the most likely primary cause of the cardiac arrest and was recorded as medical/traumatic cause/drug overdose/drowning/electrocution/asphyxia/not recorded. The arrest location was defined as the specific location where the event occurred or where the patient was found. It was recorded as public or non-public. The first monitored rhythm was defined as the first cardiac rhythm present when the monitor or defibrillator was attached to the patient after a cardiac arrest, and it was recorded as VF/pulseless VT/PEA/asystole. Bystander CPR was defined as CPR performed by a person who did not respond as part of an organized emergency response system to a cardiac arrest. The response time was defined as the time interval between the incoming call and the time when the first emergency response vehicle stopped at a point closest to the patient's location. The defibrillation time was defined as the time interval between the incoming call and the time when the first shock was delivered. The number of shocks was defined as the number of shocks delivered [13].

Prehospital ROSC was defined as the achievement of ROSC at any point during the prehospital resuscitation attempt, and any ROSC was defined as the achievement of ROSC at any point during the entire resuscitation attempt. Survival at hospital arrival was defined as the patients' being alive upon arrival at 
the hospital, and survival to discharge was defined as the patients' being alive when they were discharged.

The call-to-amiodarone administration interval and the call-to-epinephrine administration interval were defined as the time intervals between the incoming call and the time each drug was first administered.

\section{Statistical power calculation}

Statistical power analysis was performed using G*power 3.1 on a good neurological outcome at discharge rate for a two-tail logistic regression. Given the sample size of 134 , a type 1 error of 0.05 , good neurological outcome at discharge rates of 22.4 and $4.7 \%$ for the call-to-amiodarone administration intervals of $\leq 20 \mathrm{~min}$ and $>20 \mathrm{~min}$, respectively, the statistical power of 0.99 was calculated.

\section{Statistical analysis}

Statistical analyses were performed using SPSS software for Windows (V.20.0 K, SPSS, Chicago, IL, USA). Nominal data were presented as frequencies and percentages; continuous variables were presented as the mean and standard deviation (SD) and median and interquartile range (IQR) after assessments for normality using the Shapiro-Wilk test. The chi-square test or Fisher's exact test was used for comparisons of nominal variables, while the independent t-test and the Mann-Whitney U test were used to compare continuous variables. $P$-values less than 0.05 were considered statistically significant.

Univariate logistic regression analysis was performed to identify the relation between the probability of a good neurological outcome at hospital discharge and the time elapsed between the incoming call and amiodarone administration.

Multivariate logistic regression analysis was performed to identify independent factors of neurological outcome at hospital discharge, as measured by the estimated odds ratio (OR) with $95 \%$ confidence intervals (CIs). Age, sex, public place, witnessed arrest, bystander CPR, targeted temperature management (TTM), the call-to-epinephrine administration interval, and the call-to-amiodarone administration interval were included in the multivariable logistic regression analysis. Variables with a $p$-value of less than 0.2 on univariate analyses, as well as clinically relevant variables were entered into the forward stepwise multiple logistic regression models.

The receiver operating characteristic (ROC) curve was used to obtain the optimal cut-off value of the call-toamiodarone administration interval and call-toepinephrine administration interval. According to these values, the patients were divided into two groups.

\section{Result}

There were 11,210 cardiac arrest patients during the study period, and a total of 3508 patients were eligible for prehospital drug administration. Among them, 606 showed initial VF rhythm, and 134 patients who did not respond to three or more electrical defibrillation attempts were included in this study (Fig. 1).

The patients were divided into two groups according to the neurological outcome at hospital discharge. Age (51[36-65 IQR] vs 61[49-84 IQR], $p=0.009)$ and the call-to-amiodarone administration interval (19 [18-22 IQR] vs 23 [19-28 IQR], p=0.009) showed statistical significance (Table 1; Fig. 2).

In univariate logistic regression, the probability of a good neurological outcome at hospital discharge decreased as the call-to-amiodarone administration interval increased (OR $0.89 \quad[95 \% \quad \mathrm{CI}=0.80-0.99]$ ) (Fig. 3). The optimal cut-off value of the call-toamiodarone administration interval was obtained using the ROC curve analysis (AUC 0.707, 95\% CI $0.622-0.782, p<0.001)$, and the patients were divided into two groups, according to the optimal cut-off value $(\leq 20$, sensitivity 73.33 , specificity 68.07 ). As a result, there were significant differences between the two groups regarding prehospital ROSC, survival at hospital arrival, any ROSC, survival at admission, survival to discharge, and good CPC at hospital discharge (Table 2).

In multivariate logistic regression, TTM (OR 5.86, 95\% CI 1.27-27.09) and the call-to-amiodarone administration interval $\leq 20 \mathrm{~min} \quad(\mathrm{OR} \quad 10.12,95 \%$ CI 1.37-74.92) were the independent factors affecting the neurological outcome at hospital discharge (Fig. 4).

\section{Discussion}

Early amiodarone administration (call-to-amiodarone administration interval $\leq 20 \mathrm{~min}$ ) was an independent factor related to good CPC at discharge in OHCA patients who showed initial VF and subsequent RVF.

There have been some studies regarding amiodarone and OHCA outcomes. Kudenchuk et al. reported that amiodarone use in OHCA patients with refractory ventricular arrhythmias resulted in a higher rate of survival to hospital admission [14]. Dorian et al. reported that, compared with lidocaine, amiodarone led to substantially higher rates of survival at hospital admission in patients with shock-resistant out-ofhospital ventricular fibrillation [15].

Similarly, a recent large randomized trial reported that epinephrine administration increases the 30-day survival rate [16]. However, according to a study on 


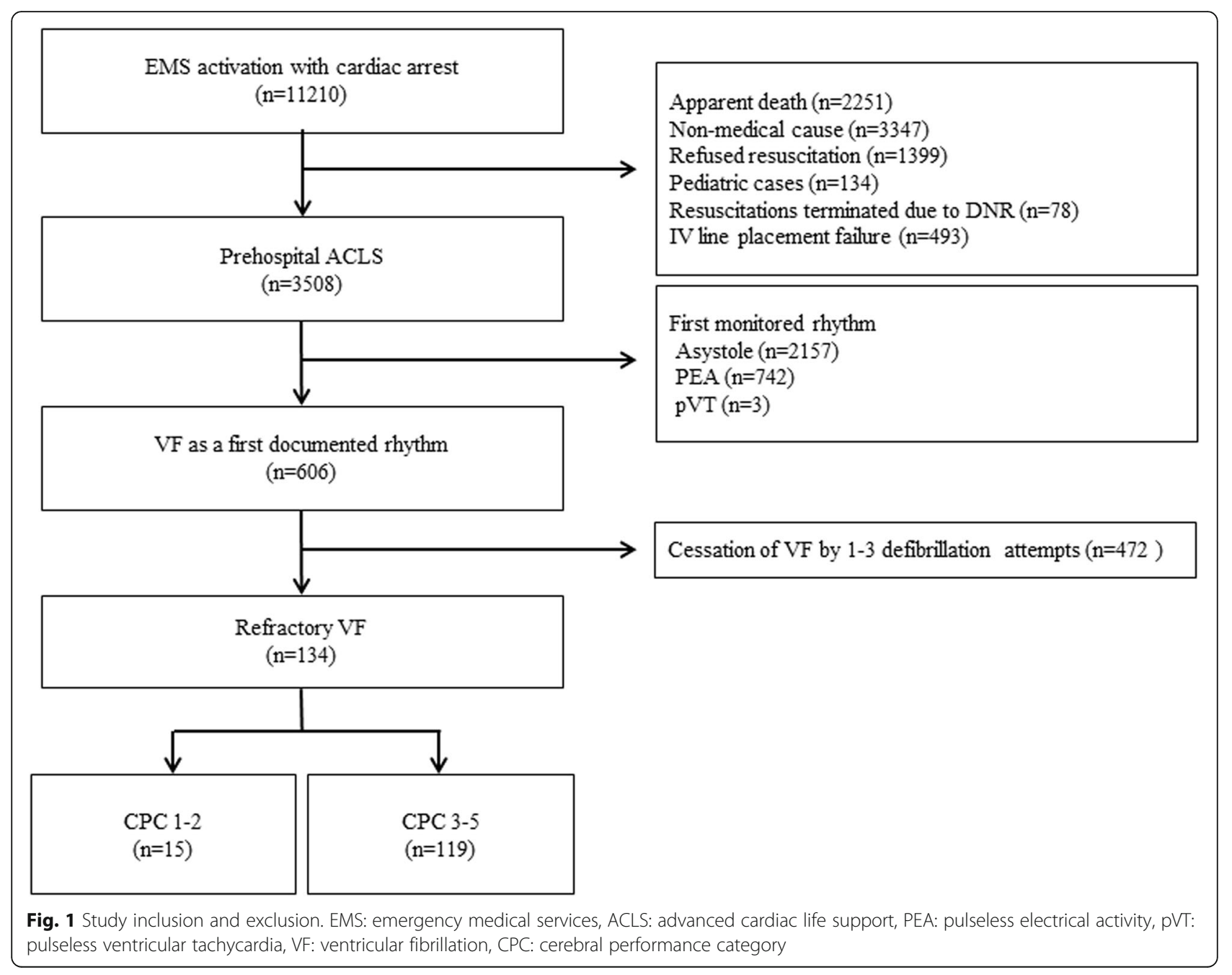

the epinephrine administration time by Hayashi et al., the neurological outcome could be improved if epinephrine were administered within $10 \mathrm{~min}$ [17].

Since there was no study on the effect of amiodarone administration time on OHCA outcomes, we evaluated the call-to-amiodarone administration interval to investigate its effect on neurological outcomes in RVF patients. As a result, early amiodarone administration revealed good neurological outcomes at hospital discharge.

VF increases myocardial oxygen demand [18]. Therefore, delayed defibrillation leads to progressive energy imbalance and causes profound intramyocardial acidosis, along with the depletion of high-energy nucleotides [19]. An animal experiment showed that greater hypercarbic acidosis or hypoxia required the highest dose of electrical energy for defibrillation and led to a greater number of failed resuscitation attempts [20]. Therefore, the AHA guidelines emphasize early defibrillation $[21,22]$.
Intramyocardial acidosis and end-organ damage may result from prolonged hypoperfusion [14] and may progress over time. For this reason, early amiodarone administration is aimed to facilitate the restoration and maintenance of a spontaneous perfusing rhythm in concert with the shock termination of VF [15], showing improvement in the neurological outcome at hospital discharge. Moreover, this result is also consistent with the 2018 AHA guidelines, which state that amiodarone may be particularly useful for those who are administered the drug early on [23].

Some studies reported that rapid defibrillation increased the rate of survival to hospital discharge [2, 24-26]. In this study, however, no difference was observed regarding the defibrillation time between the Good-CPC group and the Poor-CPC group. Given that RVF is not terminated by electrical defibrillation as a definition, this result could be acceptable. 
Table 1 Clinical and EMS ${ }^{a}$ characteristics

\begin{tabular}{|c|c|c|c|c|}
\hline \multirow[t]{2}{*}{ Characteristics } & \multirow{2}{*}{$\begin{array}{l}\text { Total } \\
(n=134)\end{array}$} & \multicolumn{2}{|c|}{ Neurological outcome at hospital discharge } & \multirow{2}{*}{$\begin{array}{l}p- \\
\text { value }\end{array}$} \\
\hline & & $\begin{array}{l}\text { Good-CPC }{ }^{b} \text { group } \\
(n=15)\end{array}$ & $\begin{array}{l}\text { Poor-CPC } C^{b} \text { group } \\
(n=119)\end{array}$ & \\
\hline Age, median (IQR') & $60(48-71)$ & $51(36-65)$ & $61(49-84)$ & 0.009 \\
\hline Male, n (\%) & $114(85.1)$ & $14(93.3)$ & $100(84.0)$ & 0.343 \\
\hline Hypertension, n (\%) & $33(24.6)$ & $5(33.3)$ & $28(23.5)$ & 0.524 \\
\hline Diabetes, n (\%) & $24(17.9)$ & $1(6.7)$ & $23(19.3)$ & 0.306 \\
\hline Cerebrovascular disease, n (\%) & $3(2.2)$ & $0(0)$ & $3(2.2)$ & 1.000 \\
\hline Heart disease, n (\%) & $26(19.4)$ & $2(13.3)$ & $24(20.2)$ & 0.735 \\
\hline Arrest location - Public space, n (\%) & $56(41.8)$ & $9(60.0)$ & $47(39.5)$ & 0.131 \\
\hline Witnessed arrest, n (\%) & $91(67.9)$ & $11(73.3)$ & $80(67.2)$ & 0.774 \\
\hline Bystander CPR ${ }^{\mathrm{d}}, \mathrm{n}(\%)$ & $105(78.4)$ & $14(93.3)$ & $91(76.5)$ & 0.137 \\
\hline Response time (minutes) & $7(6-9)$ & $7(6-11)$ & $7(6-15)$ & 0.441 \\
\hline Defibrillation time (minutes) & $11(9-13)$ & $10(9-17)$ & $11(9-20)$ & 0.205 \\
\hline Number of shocks & $7(5-9)$ & $6(4-7)$ & $7(5-9)$ & 0.421 \\
\hline TTM", n(\%) & $15(11.2)$ & $6(40.0)$ & $9(7.6)$ & 0.002 \\
\hline Call-to-amiodarone administration interval (minutes) & $23(19-26.3)$ & $19(18-22)$ & $23(19-28)$ & 0.009 \\
\hline Call-to-epinephrine administration interval (minutes) & $18(15-22)$ & $17(15-19)$ & $18(15-22)$ & 0.113 \\
\hline
\end{tabular}

${ }^{\mathrm{a}} E M S$ Emergency medical service, ${ }^{\mathrm{b}} C P C$ Cerebral performance category, ${ }^{\mathrm{C}} I Q R$ Interquartile range, ${ }^{\mathrm{d}} C P R$ Cardiopulmonary resuscitation, ${ }^{\mathrm{e}} T T M$ Targeted temperature management

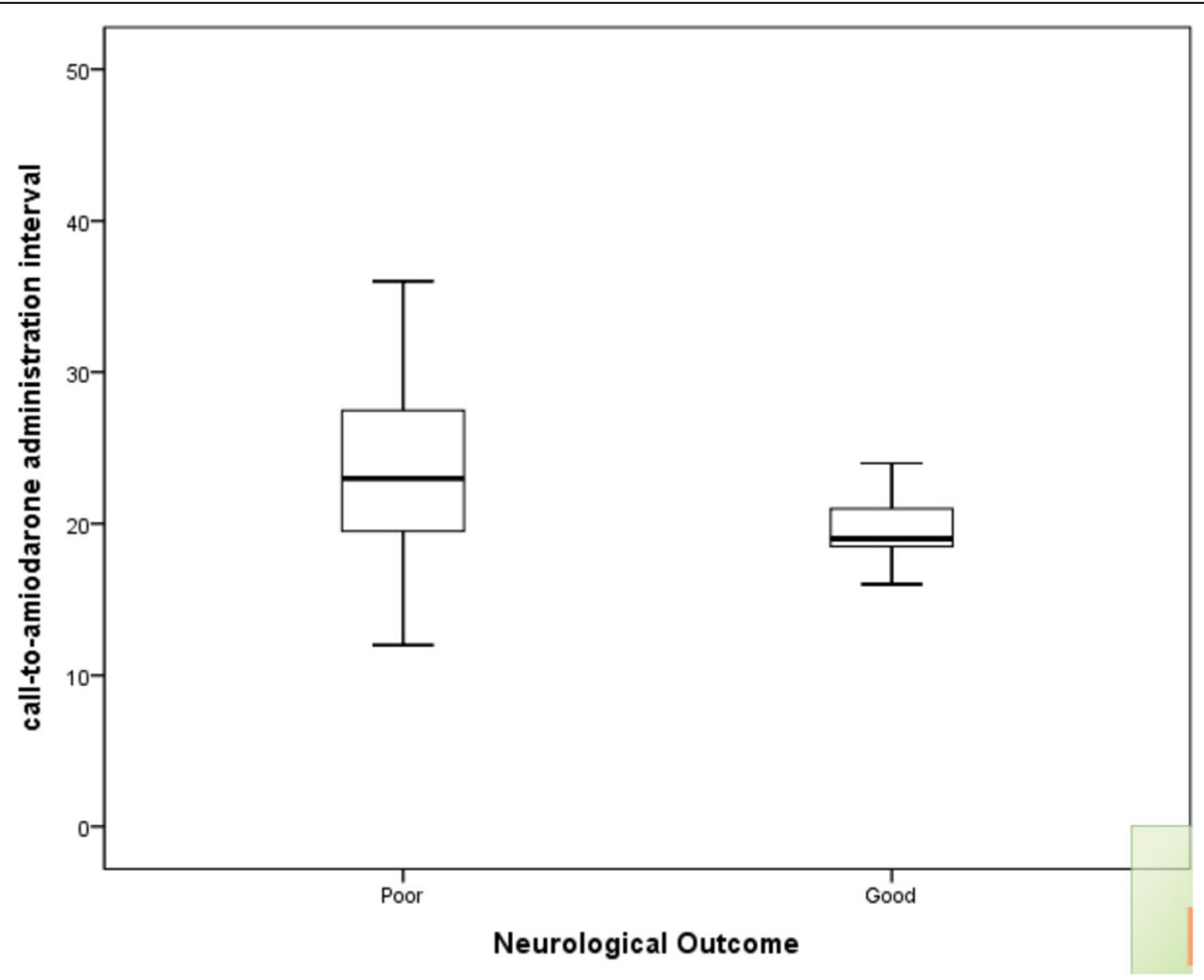

Fig. 2 Box-Whisker plot of the call-to-amiodarone administration interval 


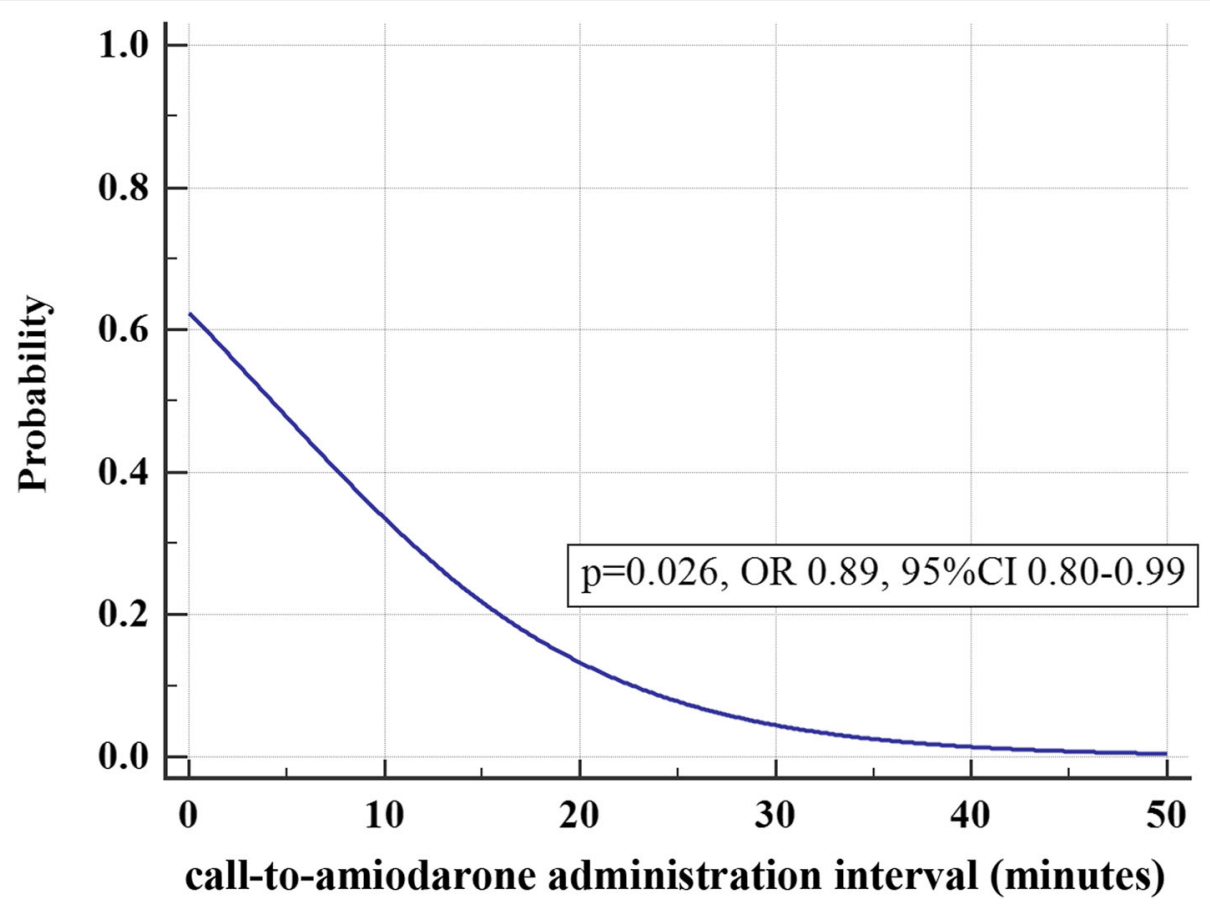

Fig. 3 Univariate logistic regression for the probability of good neurological outcome at hospital discharge according to the call-to-amiodarone administration interval. OR: odds ratio, Cl: confidence interval

Table $2 \mathrm{OHCA}^{\mathrm{a}}$ outcomes according to the call to amiodarone time

\begin{tabular}{|c|c|c|c|c|}
\hline \multirow[t]{2}{*}{ Outcomes } & \multirow[t]{2}{*}{$\begin{array}{l}\text { Total } \\
(n=134)\end{array}$} & \multirow{2}{*}{$\begin{array}{l}\text { Call-to- } \\
\text { amiodarone } \\
\text { administration } \\
\text { interval } \\
\leq 20 \text { min } \\
(n=49)\end{array}$} & \multirow{2}{*}{$\begin{array}{l}\text { Call-to- } \\
\text { amiodarone } \\
\text { administration } \\
\text { interval } \\
>20 \text { min } \\
(n=85)\end{array}$} & \multirow[t]{2}{*}{$p$-value } \\
\hline & & & & \\
\hline $\begin{array}{l}\text { Prehospital any } \\
\text { ROSC }^{b}, \mathrm{n}(\%)\end{array}$ & 48 (35.8) & $23(46.9)$ & $25(29.4)$ & 0.042 \\
\hline $\begin{array}{l}\text { Survival at } \\
\text { hospital arrival }\end{array}$ & 26 (19.4) & 15 (30.6) & $11(12.9)$ & 0.013 \\
\hline $\begin{array}{l}\text { Any ROSC } \\
\text { n (\%) }\end{array}$ & $55(41.0)$ & $26(53.1)$ & $29(34.1)$ & 0.025 \\
\hline $\begin{array}{l}\text { Survival } \\
\text { admission, } \\
\mathrm{n}(\%)\end{array}$ & 37 (27.6) & $22(44.9)$ & 15 (17.6) & 0.001 \\
\hline $\begin{array}{l}\text { Survival to } \\
\text { discharge, } \\
\text { n (\%) }\end{array}$ & $24(17.9)$ & 14 (28.6) & 10 (11.8) & 0.019 \\
\hline $\begin{array}{l}\text { Good } C^{C} C^{C} \text { at } \\
\text { hospital } \\
\text { discharge, } \\
\text { n (\%) }\end{array}$ & 15 (11.2) & $11(22.4)$ & $4(4.7)$ & 0.004 \\
\hline
\end{tabular}

Amiodarone was supposed to be given when VF persisted despite three defibrillation attempts. Because only patients who showed initial VF were enrolled in this study, the time when the amiodarone administration was decided would have been similar. Therefore, the call-to-amiodarone administration interval could have been determined mainly by response time and vascular access time. Given that no difference was observed in response time and the drugs are gated by the vascular access time, the latter may be an important factor. Therefore, when IV access is not available, alternative drug administration routes, such as intraosseous, should be considered.

There are some limitations to the present study. First, it was a retrospective study, and a six-month neurological outcome was not investigated. Second, we could not investigate the mechanisms by which the earlier amiodarone administration exerted its salutary effect in this study. However, despite the fact that the definition of RVF varies and the optimal interval between the incoming call and amiodarone administration has not been fully established yet, the result of this study remains compelling. Third, we could not investigate the adverse effects of amiodarone. Last, the treatment of patients after hospitalization was not standardized. Although the patients were treated in accordance with the 2015 AHA guidelines, post- 


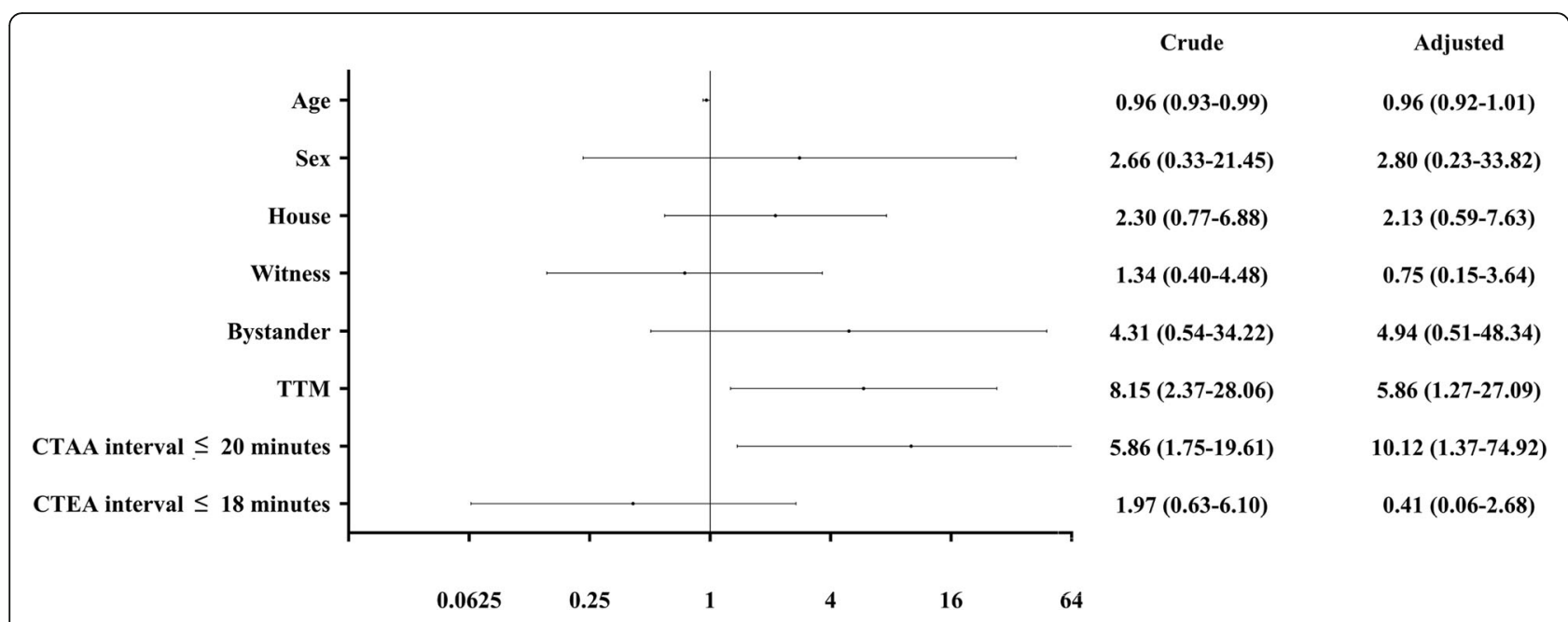

Fig. 4 Multivariate logistic regression for the probability of good neurological outcome at hospital discharge. TTM: targeted temperature management, CTAA: call-to-amiodarone administration, CTEA: call-to-epinephrine administration

resuscitation management followed the protocol of each institution.

\section{Conclusion}

Early amiodarone administration $(\leq 20 \mathrm{~min})$ resulted in better neurological outcomes at hospital discharge for OHCA patients who presented with initial VF and subsequent RVF.

\section{Acknowledgements}

The authors thank Division of Statistics in Medical Research Collaborating Center at Seoul National University Bundang Hospital for statistical analyses.

\section{Authors' contributions}

Conceptualization: DKLee. Data curation: DKLee, YJKim. Formal analysis: DKLee, YTOh. Investigation: SMPark, YTOh, JOh. Methodology: DKLee, JOh. Project administration: SMPark, YJKim. Resources: CALee, HJMoon, SMPark, YJKim, GKim. Supervision: SMPark. Validation: DKLee, SMPark. Visualization: HCYang. Writing - original draft: DKLee. Writing - review \& editing: YTOh. All authors read and approved the final manuscript.

\section{Funding}

The authors declare that they have no funding source.

\section{Availability of data and materials}

Data sharing is not applicable to this article as no datasets were generated or analysed during the current study.

\section{Ethics approval and consent to participate}

This study was approved by the Institutional Review Board (IRB) of Seoul National University Bundang Hospital (IRB approval number: B-1904-537-103). The informed consent was waived.

\section{Consent for publication}

Not applicable.

\section{Competing interests}

The authors declare that they have no competing interests.

\section{Author details}

'Department of Emergency Medicine, Seoul National University Bundang Hospital, 1362082, Gumi-ro 173 Beon-gil, Bundang-gu, Seongnam-si, Gyeonggi-do, Republic of Korea. ${ }^{2}$ Department of Emergency Medicine, Soonchunhyang University Bucheon Hospital, 170 ,Jomaru-ro, Wonmi-gu,
Bucheon-si 14584, Gyeonggi-do, Republic of Korea. ${ }^{3}$ Department of Emergency Medicine, Hallym University Dongtan Sacred Heart Hospital, 7, Keunjaebong-gil, Hwaseong-si 18450, Gyeonggi-do, Republic of Korea. ${ }^{4}$ Department of Emergency Medicine, Soonchunhyang University Cheonan Hospital, 31, Suncheonhyang 6-gil, Dongnam-gu, Cheonan-si 31151, Chungcheongnam-do, Republic of Korea. ${ }^{5}$ Department of Emergency Medicine, College of Medicine, Hanyang University, 222-1, Wangsimni-ro, Seongdong-gu, Seoul 04763, Republic of Korea. ${ }^{6}$ Researcher, Seoul National University Bundang Hospital, 82, Gumi-ro 173beon-gil, Bundang-gu, Seongnam-si 13620, Gyeonggi-do, Republic of Korea. ${ }^{7}$ Department of emergency medicine, Dankook University College of Medicine, 201 Manghyang-ro, Dongnam-gu, Cheonan-si 31116, Chungcheongnam-do, Republic of Korea.

Received: 26 July 2019 Accepted: 20 November 2019

Published online: 10 December 2019

\section{References}

1. Jentzer JC, Clements $C M$, Wright RS, White RD, Jaffe AS. Improving survival from cardiac arrest: a review of contemporary practice and challenges. Ann Emerg Med. 2016:68:678-89.

2. Sasson C, Rogers MAM, Dahl J, Kellermann AL. Predictors of survival from out-of-hospital cardiac arrest: Circulation: Cardiovascular Quality and Outcomes; 2010. p. 63-81. Available from. https://doi.org/10.1161/ circoutcomes.109.889576.

3. Maio VJD, De Maio VJ, Stiell IG, Wells GA, Spaite DW. Optimal defibrillation response intervals for maximum out-of-hospital cardiac arrest survival rates. Ann Emerg Med. 2003;42:242-50. Available from: https:/doi.org/10.1067/mem.2003.266.

4. Stiell IG, Nichol G, Leroux BG, Rea TD, Ornato JP, Powell J, et al. Early versus later rhythm analysis in patients with out-of-hospital cardiac arrest. N Engl J Med. 2011;365:787-97.

5. Yannopoulos D, Bartos JA, Raveendran G, Conterato M, Frascone RJ, Trembley $A$, et al. Coronary artery disease in patients with out-of-hospital refractory ventricular fibrillation cardiac arrest. J Am Coll Cardiol. 2017;70:1109-17.

6. Sakai T, Iwami T, Tasaki O, Kawamura T, Hayashi Y, Rinka H, et al. Incidence and outcomes of out-of-hospital cardiac arrest with shock-resistant ventricular fibrillation: data from a large population-based cohort. Resuscitation. 2010;81:956-61.

7. Link MS, Berkow LC, Kudenchuk PJ, Halperin HR, Hess EP, Moitra VK, et al. Part 7: adult advanced cardiovascular life support: 2015 American Heart Association guidelines update for cardiopulmonary resuscitation and emergency cardiovascular care. Circulation. 2015;132:5444-64.

8. Singh BN, Vaughan Williams EM. The effect of amiodarone, a new antianginal drug, on cardiac muscle. Br J Pharmacol. 1970;39:657-67.

9. Kudenchuk PJ, Brown SP, Daya M, Rea T, Nichol G, Morrison $\sqcup$, et al. Amiodarone, Lidocaine, or Placebo in Out-of-Hospital Cardiac Arrest. N Engl 
J Med. 2016:1711-22. Available from:. https://doi.org/10.1056/ nejmoa1514204.

10. Tanaka H, Takyu H, Sagisaka R, Ueta H, Shirakawa T, Kinoshi T, et al. Favorable neurological outcomes by early epinephrine administration within 19 minutes after EMS call for out-of-hospital cardiac arrest patients. Am J Emerg Med. 2016;34:2284-90. Available from:. https://doi.org/10.1016/ j.ajem.2016.08.026.

11. Lee DK, Park SM, Kim YJ, Lee CA, Jeong WJ, Kim GW, et al. CPR Guidance by an Emergency Physician via Video Call: A Simulation Study. Emerg Med Int. 2018;2018:1-6. Available from:. https://doi.org/10.1155/2018/1480726.

12. von Elm E, Altman DG, Egger M, Pocock SJ, Gøtzsche PC, et al. The Strengthening the Reporting of Observational Studies in Epidemiology (STROBE) Statement: Guidelines for Reporting Observational Studies. PLoS Medicine. 2007:e296. Available from:. https://doi.org/10.1371/journal.pmed. 0040296.

13. Perkins GD, Jacobs IG, Nadkarni VM, Berg RA, Bhanji F, Biarent D, et al. Cardiac Arrest and Cardiopulmonary Resuscitation Outcome Reports: Update of the Utstein Resuscitation Registry Templates for Out-of-Hospital Cardiac Arrest: A Statement for Healthcare Professionals From a Task Force of the International Liaison Committee on Resuscitation (American Heart Association, European Resuscitation Council, Australian and New Zealand Council on Resuscitation, Heart and Stroke Foundation of Canada, InterAmerican Heart Foundation, Resuscitation Council of Southern Africa, Resuscitation Council of Asia); and the American Heart Association Emergency Cardiovascular Care Committee and the Council on Cardiopulmonary, Critical Care, Perioperative and Resuscitation. Resuscitation. 2015;96:328-40.

14. Kudenchuk PJ, Cobb LA, Copass MK, Cummins RO, Doherty AM Fahrenbruch $C E$, et al. Amiodarone for resuscitation after out-of-hospital cardiac arrest due to ventricular fibrillation. N Engl J Med. 1999;341:871-8.

15. Dorian P, Cass D, Schwartz B, Cooper R, Gelaznikas R, Barr A. Amiodarone as compared with lidocaine for shock-resistant ventricular fibrillation. N Engl J Med. 2002;346:884-90.

16. Perkins GD, Ji C, Deakin CD, Quinn T, Nolan JP, Scomparin C, et al. A randomized trial of epinephrine in out-of-hospital cardiac arrest. N Engl J Med. 2018:379:711-21.

17. Hayashi Y, Iwami T, Kitamura T, Nishiuchi T, Kajino K, Sakai T, et al. Impact of early intravenous epinephrine administration on outcomes following out-ofhospital cardiac arrest. Circ J. 2012;76:1639-45.

18. Yaku H, Goto Y, Ohgoshi Y, Kawaguchi O, Oga K, Oka T, et al. Determinants of myocardial oxygen consumption in fibrillating dog hearts. Comparison between normothermia and hypothermia. J Thorac Cardiovasc Surg. 1993;105:679-88.

19. Johnson BA, Weil MH, Tang W, Noc M, McKee D, McCandless D. Mechanisms of myocardial hypercarbic acidosis during cardiac arrest. J Appl Physiol. 1995;78:1579-84

20. Idris AH, Wenzel V, Becker LB, Banner MJ, Orban DJ. Does hypoxia or hypercarbia independently affect resuscitation from cardiac arrest? Chest. 1995;108:522-8.

21. Berg RA, Hemphill R, Abella BS, Aufderheide TP, Cave DM, Hazinski MF, et al. Part 5: Adult Basic Life Support: 2010 American Heart Association guidelines for cardiopulmonary resuscitation and emergency cardiovascular care. Circulation. 2010; 122:5685-705. Available from: https://doi.org/10.1161/circulationaha.110.970939.

22. Hansen CM, Kragholm K, Granger CB, Pearson DA, Tyson C, Monk L, et al. The role of bystanders, first responders, and emergency medical service providers in timely defibrillation and related outcomes after out-of-hospital cardiac arrest: Results from a statewide registry. Resuscitation. 2015;96:303-9. Available from:. https://doi.org/10.1016/j.resuscitation.2015.09.002.

23. Panchal AR, Berg KM, Kudenchuk PJ, Del Rios M, Hirsch KG, Link MS, et al. 2018 American Heart Association focused update on advanced cardiovascular life support use of antiarrhythmic drugs during and immediately after cardiac arrest: an update to the American Heart Association guidelines for cardiopulmonary resuscitation and emergency cardiovascular care. Circulation. 2018;138(23):e740-9. Available from:. https:/ doi.org/10.1161/cir.0000000000000613.

24. Rea TD, Cook AJ, Stiell IG, Powell J, Bigham B, Callaway CW, et al. Predicting Survival After Out-of-Hospital Cardiac Arrest: Role of the Utstein Data Elements. Ann Emerg Med. 2010;55:249-57. Available from:. https://doi.org/ 10.1016/j.annemergmed.2009.09.018.

25. Chan PS, Nichol G, Krumholz HM, Spertus JA, Nallamothu BK, American Heart Association National Registry of Cardiopulmonary Resuscitation (NRCPR) Investigators. Hospital variation in time to defibrillation after inhospital cardiac arrest. Arch Intern Med. 2009;169:1265-73.
26. Valenzuela TD, Roe DJ, Nichol G, Clark LL, Spaite DW, Hardman RG. Outcomes of rapid defibrillation by security officers after cardiac arrest in casinos. N Engl J Med. 2000;343:1206-9.

\section{Publisher's Note}

Springer Nature remains neutral with regard to jurisdictional claims in published maps and institutional affiliations.
Ready to submit your research? Choose BMC and benefit from:

- fast, convenient online submission

- thorough peer review by experienced researchers in your field

- rapid publication on acceptance

- support for research data, including large and complex data types

- gold Open Access which fosters wider collaboration and increased citations

- maximum visibility for your research: over $100 \mathrm{M}$ website views per year

At BMC, research is always in progress.

Learn more biomedcentral.com/submissions 